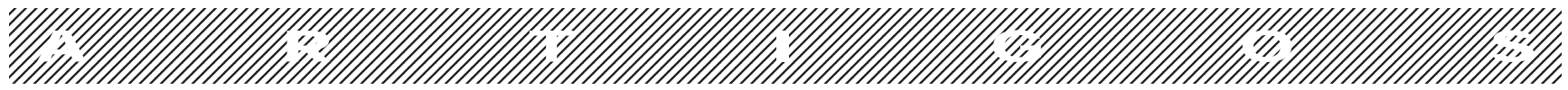

\title{
Aspectos psicossociais da imigração familiar na Grande Porto Alegre
}

\author{
Jorge Castellá Sarriera \\ Adolfo Pizzinato \\ Pontifícia Universidade Católica do Rio Grande do Sul \\ María Piedad Rangel Meneses \\ Universidade Regional Integrada do Alto Uruguai e das Missões
}

\begin{abstract}
Resumo
Neste artigo apresentam-se alguns aspectos psicossociais presentes no processo migratório de seis famílias hispano-americanas na região metropolitana de Porto Alegre. Estes aspectos, relatados através de entrevistas semi-estruturadas com os integrantes das famílias, indicam os principais tópicos que nortearam as entrevistas: suas trajetórias migracionais, decisão de imigrar, sua inserção na cultura local, suas relações comunitárias, identidade e expectativas de vida. São analisadas as formas como ocorrem as transições aculturativas no contexto local.
\end{abstract}

Palavras-chave: imigração; aculturação; família; identidade; comunidade

\begin{abstract}
Psychosocial aspects of familiar immigration at the Porto Alegre region (Brazil). On this article some psychosocial aspects included on the migratory process of six Hispanic families at the metropolitan region of Porto Alegre (Brazil) are presented. These aspects, obtained through semi-structured interviews with the members of the families that had indicated the principal topics that guided the interviews: their emigrational paths, their decision to immigrate, their insertion on the local culture, their community relations, identity and life expectations. The ways by which the acculturative transitions on the local context happen are analyzed.
\end{abstract}

Key-words: immigration; acculturation; family; identity; community

$\mathrm{E}$ ste artigo apresenta o processo migratório de seis famílias na região metropolitana de Porto Alegre. Focaliza-se a imigração atual, priorizando os aspectos psicossociais envolvidos no processo migratório de famílias hispano-americanas.

As migrações humanas são um fenômeno constante ao largo da história e não existe um povo ou nação que não seja herdeiro ou resultante de uma grande migração. Desde 1750, mais de 350 milhões de pessoas abandonaram seus países de origem para instalar-se em outro destino e, durante o século XIX, esta cifra chegou a representar quase 100 milhões, dos quais mais de $50 \%$ se vincularam a uma migração transoceânica com destino à América (EUA, Canadá, Argentina, Brasil, Cuba e Uruguai) (García, Martinez, \& Santolaya, 2002).
Em 1989, a ONU estimava em 50 milhões o número de pessoas (emigrantes, asilados, refugiados, etc.) que viviam fora de suas fronteiras de origem. As contínuas guerras, a pobreza, a perseguição política ou os desastres ecológicos fizeram que em 1992 essa cifra fosse duplicada. Assim, a imigração internacional está se convertendo em um dos desafios mais importantes para os sistemas políticos, econômicos e sociais do mundo (García, Martinez, \& Santolaya, 2002).

O Rio Grande do Sul se configura como o maior pólo receptor de imigrantes do Brasil no século XIX e o terceiro maior pólo de recepção de imigrantes do Brasil desde então (Diégues Júnior, 1964; IBGE, 2000). Porto Alegre, embora tenha tido uma fundação luso-açoriana, recebeu e incorporou muito dos principais grupos de imigrantes do estado desde o 
século XIX (Diégues Júnior, 1964). O período compreendido entre 1890 e 1914 foi responsável por mais da metade de toda a imigração oficial no Brasil até 1950.

Embora a região sul do país seja a terceira mais populosa do país (atrás das regiões sudeste e nordeste), é a segunda região em número de imigrantes e estrangeiros naturalizados. Apesar de o sul deter apenas $15,08 \%$ da população nacional, nele vivem $20 \%$ da população de estrangeiros naturalizados e $10,8 \%$ da população de estrangeiros residentes no país. Entretanto, as relações do Rio Grande do Sul com a cultura e os povos de outros países é bastante estreita desde sua formação.

Por cerca de metade dos 500 anos da conquista européia do Brasil, parte considerável do território atual do estado do Rio Grande do Sul pertenceu à Coroa Espanhola, em vez da Portuguesa. Foi apenas no ano de 1750, com o Tratado de Madri, que o estado começou adotar a forma que tem hoje (Fagundes, 1992). Isso significa que pelo menos durante metade do tempo da conquista européia, quase todo o território era "castelhano". A "lusificação" do mito e da historiografia referente às origens do povo gaúcho começou a adquirir força nos períodos revolucionários do estado (1825, 1893, 1923 e, finalmente, 1930), culminando no período do Estado Novo (Albeche, 1996). Essa lusificação da identidade gaúcha, além dos fins políticos e ideológicos, gerou uma negação de qualquer participação hispânico-platina ou indígena na construção da identidade histórica, reforçada pelo posterior Movimento Tradicionalista Gaúcho (Albeche, 1996).

Outro elemento que reforça a presença castelhana no estado se observa em dados mais atuais. Estatísticas do Departamento de Polícia Federal (Divisão de Polícia Marítima, Aeroportuária e de Fronteiras, Serviço de Registro de Estrangeiros), apontam que o número de estrangeiros cadastrados no estado, até abril de 2000, era de 44.022 (quarenta e quatro mil e vinte e dois), independente de imigração definitiva. Os principais grupos de estrangeiros vivendo no RS até a data apontada eram: uruguaios: 18023; argentinos: 3490; portugueses: 2772; alemães: 2429; italianos: 2336; norte-americanos: 1886; japoneses: 1412; chilenos: 1405; espanhóis: 1278 e poloneses: 949.

Esses dados caracterizam a população gaúcha de imigrantes como predominantemente platina, além de expressivos números da população dos principais grupos étnicopopulacionais que colonizaram o estado até o século XIX: portugueses, alemães e italianos. Assim, parece que nossas raízes históricas de interface relacional com outros grupos humanos não estão tão distantes. A imigração no Rio Grande do Sul é uma importante questão social, não apenas em termos passados, mas uma questão bastante presente.

Falar em imigração implica automaticamente em falar sobre cultura. O que é entendido pelo termo cultura, em qualquer que seja o campo de aplicação, sempre é muito fértil em significados.

Segundo Sciarra (1999), em se tratando da psicologia moderna, este conceito evoluiu de formas diferentes nos últi- mos cinqüenta anos. Nos anos 50, a cultura era definida em termos de padrões de hábitos e comportamentos, enfocando os aspectos observáveis da cultura (como vestuário, idioma, alimentação), ignorando que pudessem ser apenas manifestações de outros níveis ignorados desta (Sciarra, 1999).

Nesse sentido, a psicologia parece ter despertado tardiamente para a construção de novas reflexões e conhecimentos acerca de suas relações com a cultura. Entretanto, todos estes termos e acepções são originários de outras áreas do conhecimento, tais como a antropologia, sociologia e educação, e só recentemente passaram a ser mais bem teorizados e principalmente investigados pela psicologia, principalmente a psicologia social (Berry, 2001; Gregório Gil, Díaz-Gómez, \& Rivas Nina, 1994; Sabatier \& Berry, 1996).

Os estudos culturais, multiculturais e transculturais na psicologia abarcam uma imensa gama de tópicos. Mais especificamente, entretanto, na psicologia social é que se desenvolveu, nos últimos vinte anos, um campo disciplinar chamado psicologia intercultural (e/ou transcultural), conforme apontam Sabatier e Berry (1996) e Sarriera (2000).

Este campo do conhecimento psicossocial se constituiria baseado nos estudos dedicados a descrever e compreender a influência dos fatores culturais no desenvolvimento e nos comportamentos. Influência esta que seria traduzida em termos da diversidade, através do mundo, das condutas e dos comportamentos cotidianos (Bhattacharya, 2000; McLaren, 1995; Sabatier \& Berry, 1996). Corolariamente, um segundo foco deste campo de conhecimento consistiria na análise da adaptação psicológica dos indivíduos e grupos quando mudam de cultura.

Enquanto processo social, a migração pode ser entendida como um complexo fenômeno que envolve mudança não apenas de endereço (após cruzar a fronteira de uma unidade administrativa), mas de toda uma série de contatos socioculturais do indivíduo, em todas as áreas de sua vida. O estresse psicológico inerente a mudanças, torna o imigrante particularmente vulnerável aos riscos de morbidade diferencial em seu novo ambiente, ainda mais se este ambiente deslocar-se para uma área densamente urbanizada, onde enfrentarão riscos ambientais diferentes daqueles experimentados antes de emigrar (Mota, Franco, \& Motta, 1999).

Nesse sentido, e considerando os postulados teóricos sobre as implicações psicossociais dos processos migratórios, o Grupo de Pesquisa em Psicologia Comunitária da PUCRS desenvolveu uma investigação buscando conhecer melhor este segmento significativo da comunidade porto-alegrense e imediações.

A linha de investigação pretendida pela presente investigação entra em sintonia com o escopo de investigações realizadas na área, em diferentes contextos (Bhattacharya, 2000; Gregorio Gil, Díaz-Gómez, \& Rivas Nina, 1994; Sabatier \& Berry, 1996; Zepeda, 2000), nas quais a situação de inserção e as formas de relação com a comunidade de acolhida e com a cultura majoritária são a tônica principal.

Assim, buscou-se através desta pesquisa conhecer um pouco mais sobre as motivações e vicissitudes do processo 
migratório de famílias hispano-americanas na região metropolitana de Porto Alegre.

\section{Método}

\section{Participantes}

Foram participantes desta investigação seis famílias imigrantes hispano-americanas, moradoras na região metropolitana de Porto Alegre, escolhidas intencionalmente através do serviço de acolhida ao imigrante mantido pela Paróquia de Nossa Senhora da Pompéia (Porto Alegre). Embora as famílias tenham sido contatadas através do serviço mantido pela Igreja, essa vinculação não era necessariamente religiosa, mas sim assistencial. Participaram famílias constituídas por um número entre 2 e 13 participantes, advindas de países sulamericanos (Uruguai, Colômbia, Chile, Peru e Argentina), com um tempo no Brasil entre 2 meses e 12 anos, cuja intenção de saída do país foi migração permanente, independentemente do fato de terem sua situação regulamentada pela legislação brasileira.

\section{Procedimento}

Através de contatos telefônicos e pessoais estabelecidos com várias famílias, seis delas aceitaram participar da investigação. A coleta dos dados deu-se através de entrevistas semi-estruturadas, realizadas em local combinado com as famílias (suas residências ou nas dependências da igreja), sempre com a participação do maior número possível de membros da família e dois dos pesquisadores. Os tópicos que nortearam a entrevista foram suas trajetórias migracionais, decisão de imigrar, sua inserção na cultura local, suas relações comunitárias, identidade e expectativas de vida.

Todas as entrevistas foram gravadas e transcritas na íntegra, com autorização prévia das famílias consultadas. Tais entrevistas são identificadas no presente trabalho apenas por um número. A partir dos relatos obtidos nas entrevistas realizou-se uma análise categorial, conforme o método proposto por Clemente-Díaz (1992), com o intuito de levantar as categorias que caracterizassem expressivamente o processo migratório.

A análise categorial, segundo Clemente-Díaz (1992), permite "analisar conteúdos e extrair informações, partindo do material recolhido em um suporte específico, sendo realizada cientificamente, mediante procedimentos confiáveis, válidos e derivados de um conjunto de noções teóricas determinadas” (p. 169). As categorias que surgiram permitem compreender a trajetória do processo migracional das famílias e, a partir dessa compreensão, obtém-se uma caracterização do processo psicossocial de migração. Assim, configuraram-se na análise quatro eixos categoriais básicos: (a) a decisão de emigrar; (b) a inserção na cultura local; (c) relações comunitárias; e (d) identidade e expectativas de vida. Esses eixos emergiram a partir das entrevistas indicando que, embora as categorias aparentemente não expressem novidade, o conteúdo representa alguns avanços no estudo da migração.

\section{Resultados e discussão}

\section{A decisão de emigrar}

Todas as famílias estudadas migraram para o Brasil com o intuito de não voltar definitivamente para seus países de origem. De acordo com Klein (1999), para o entendimento do fenômeno social da imigração, devem-se tomar em consideração predominantemente dois tipos de fatores: os de expulsão e os de atração; ambos com múltiplas nuanças. Em tese, poucas pessoas possuem um desejo absolutamente imanente de emigrar, de abandonar sua casa, ou entorno social, conforme apontam as pesquisas de Boneva e Frieze (2001). Emigram normalmente por razões de manutenção da qualidade de vida e na tentativa de viver de forma tradicional como o faziam em suas comunidades de origem, por exemplo (Klein, 1999).

Nesse sentido, as famílias estudadas apresentam a melhora da qualidade de vida como o motivo central de sua vinda para o Brasil. A qualidade de vida é objetivada por tais famílias através do desejo de incrementar as rendas financeiras do grupo, incremento das possibilidades de inserção laboral e principalmente para fugir da violência e do desemprego em seus países de origem. Verbalizações neste sentido foram dadas por todas as famílias. Apresentam-se a seguir algumas falas representativas:

As razões pelas que eu vim foram os maus tratos físicos, psicológicos e sexuais... (Família 3)

Meu marido sempre queria buscar um novo lugar, novos horizontes, queria sair do país porque é sempre tão pobre, tão empobrecido. (Família 5)

Estávamos procurando através de bens materiais, coisas que todo mundo quer ter, coisas básicas. Quisera ter a condição econômica, conseguir um trabalho e comprar um refrigerador para ela, um fogão, um sofá... A prioridade era o emprego, para dar que comer a meus filhos. (Família 3)

O problema é a política, né? Lá tinha um presidente, ganhou outro partido e então ele tirou todo o pessoal que ele quis para botar a gente dele. Fiquei na rua, sem nada do dia para a noite. (Família 4)

Aí a gente tinha muito problema, também, o clima, ai, também a guerra, as coisas, não podíamos ficar mais lá. (Família 1)

A gente tinha a expectativa de que... de melhorar né? A gente tava vendo que lá não tinha muita possibilidade de melhorar de crescer, sei lá. De buscar novos... não sei, expectativa de vida, melhora de vida, de crescer economicamente. (Família 2)

Entretanto, normalmente existem alguns fatores que impossibilitam que se possa viver como o idealizado, ou desejado em suas comunidades de origem, buscando então uma mudança física, nem sempre acompanhada de desejo de mudanças culturais (Klein, 1999). O mais complexo dos níveis de entendimento do processo migratório é o econômico, embora 
no período das grandes migrações tenha sido o mais bem caracterizado pela historiografia. Acredita-se que esta caracterização dos fatores econômicos de expulsão tenha ainda uma dimensão válida para a compreensão destes fatores hoje. Fatores econômicos de expulsão podem ser caracterizados por: (a) acesso a terra ou a emprego/alimentação; (b) variação da produtividade agrícola e/ou industrial e (c) número de filhos ou dependentes (Klein, 1999).

Já os fatores de atração que operaram principalmente nos grandes movimentos migratórios da história foram a abundância de terras e a baixa densidade demográfica e/ou grande oferta de trabalho (Klein, 1999). É claro que tal configuração contextual não se aplica à situação da imigração nos dias de hoje. O Rio Grande do Sul e em especial a Região Metropolitana de Porto Alegre não podem, de forma alguma, serem conceituados como regiões de baixa densidade populacional ou com espaço geográfico devoluto em abundância. O nível de análise da realidade atual é mais complexo.

Recentemente, Pereda e colaboradores (Pereba, Prada, \& Actis, 1999) apontaram a necessidade de entender os fluxos migratórios atuais no marco da globalização como estrutura de uma nova ordem social e política. Concretamente, se referem tanto ao que os autores denominam como inevitabilidade do mercado (competência e mercado), como ao processo de mundialização, mediante ao qual se romperam as barreiras do capital, dos bens e serviços e informações, mas não a força do trabalho. Nesse contexto, os processos migratórios atuais se caracterizariam por: (a) sua diversidade: indivíduos $\mathrm{x}$ grupos familiares; fluxos econômicos x políticos; diversidade racial, destino sul-norte x sul-sul (como o caso específico da América Latina); analfabetos x alta qualificação, etc; (b) universalidade; (c) feminização, e (d) políticas restritivas que conduzem a novas modalidades de entrada nos países receptores e a um aumento da clandestinidade dos fluxos. Nesse sentido, pode-se observar ainda nas presentes famílias que, além da caracterização de imigração atual, a recorrência da imigração na história familiar é um fator presente.

Nos relatos das famílias encontra-se que a necessidade econômica no país de origem é um dos fatores precursores da migração, porém, ao chegarem ao país de acolhida, nem todos eles têm garantido seu emprego e lugar no mercado laboral. Isto porque é no país de acolhida que as regras trabalhistas são estabelecidas e a voz dos imigrantes não é escutada. Nesse sentido, seguindo Sayad (1998), os países são soberanos e eles impõem as formas de negociação, ficando em posição de dominação sobre o imigrante que, pela própria condição de desconhecimento das leis, das gestões burocráticas, dificuldade da língua, entre outros, está impossibilitado para negociar. Por outro lado, as próprias condições dos países de acolhida, neste caso o Brasil, podem passar por momentos de crise econômica, elevando a taxa de desemprego dos nacionais, tanto mais dos imigrantes. Para muitos imigrantes, o que permanece e mobiliza a migração é a ilusão de melhorar, levando-os a casos de submissão e subemprego, como no caso dos argelinos pesquisados por Sayad (1998).

Observou-se que todas as famílias tinham uma experiência migracional prévia, seja internacional ou nacional e nos dois casos em que os integrantes da família moravam nas fronteiras, a migração estava “naturalizada”. Este aspecto da experiência familiar é caracterizado nas falas das famílias entrevistadas em situações como:

\begin{abstract}
Anteriormente estávamos em Buenos Aires, levamos os menores (filhos), mas as coisas não se deram como pensávamos... Não tinha trabalho, um amigo nos emprestou um apartamento e estivemos lá 2 anos. Depois regressamos a Montevidéu... Depois andamos por Austrália e Nova Zelândia, mas não nos deram os vistos e meus irmãos estavam se dando bem por cá... (Família 5)
\end{abstract}

Tem primos, filhos da minha prima que foram para os Estados Unidos, para Canadá, para Argentina... meu tio mora faz 30 anos nos Estados Unidos e meu irmão mora faz 7 anos aqui... em todos os casos a experiência foi positiva, foi melhor... Casaram, melhoraram bastante de vida, tem trabalho. Deramse bem! (Família 4)

Meu pai pediu demissão no Chile e veio para Brasil em 78. Eu não sei por que vim. Eu tinha que ir aonde meus pais iam; ninguém me falou nada. Meu pai queria emprego e fugir do governo militar... Já tinha tentado antes, por duas vezes passou tempos na Venezuela... (Família 3)

Minha mãe é brasileira e morou na Colômbia 30 anos. Meu pai veio de Espanha e ficou na Colômbia. (Família 1)

Nós morávamos no interior e depois fomos para a capital para fazer a faculdade. (Família 1)

Falar de família na atualidade nos leva a falar de diversidade e, dentro do marco em que se propõe este artigo, de diversidade cultural. Além da pluralidade com que devemos nos referir à instituição familiar, é certo que as definições de família, por mais variadas que sejam, residem hoje nas relações interindividuais, dando a idéia de que a família é, antes de tudo, um projeto relacional, que não faz referência necessariamente a laços de sangue (González-Tornaría, 2000).

Os valores, atitudes e expectativas que desta forma se transmitem, constituem o que alguns autores (GonzálezTornaría, 2000) chamam currículo familiar. Este currículo familiar não está escrito - à diferença do escolar - mas conta com objetivos, conteúdos, “metodologias” que determinam a cifra de identidade de cada família, e contribuem para a geração de aprendizagens entre seus membros. As famílias se diferenciam não apenas pelos conteúdos, mas também nos estilos com que transmitem estes conteúdos (Martínez, 1996).

No processo migracional a formação familiar cobra um papel importante porquanto esta tem de se deslocar com os filhos, os quais muitas vezes assistem aos planos dos seus pais de saírem do país, sem ter uma participação direta. O próprio estresse produzido pela perda do contexto conhecido, pode levar os pais a não contar aos filhos, com a intenção de poupá-los do sofrimento. Porém, esses menores podem vivenciar um efeito de estranhamento, como não compreender muito bem o porquê da migração. Como indica Sayad 
(1998), o lugar que os filhos ocupam na família se constitui em fator para facilitar ou dificultar o processo de transição cultural. Isto se observou nas diversas famílias entrevistadas, no caso, por exemplo, de filhos rodando de série, manifestando problemas escolares, ou dificuldade para compreender o porquê da saída do seu país. Nas pesquisas realizadas com famílias imigrantes, o autor evidencia as diferenças importantes, devido à facilidade com que os filhos que chegam mais novos ao país de acolhida têm possibilidades mais altas de se perceber como enculturados, enquanto que para os mais velhos persistem algumas dificuldades (Sayad, 1998).

Praticamente todas as definições, não importando desde onde se posicionem para estudar a família, fazem referência aos fatores comuns: habitação comum, descendência comum, mesmo nome, mesmos pais, mesmo grupo, mesma história (González-Tornaría, 2000).

Essa história é um dos pontos principais a que pretende atender esta pesquisa, partindo do ponto da imigração de grupos étnico-culturais de diferentes bagagens que participam da formação humana do Rio Grande do Sul. Grupos com as mais distintas raízes trazem suas influências e constróem aqui uma nova perspectiva, uma nova forma de encarar a vida.

\section{A inserção na cultura local}

O processo de aprendizado de novos significados e habilidades, paralelo no sentimento de ser aceito, pode ser chamado de choque cultural. É o “choque” mais freqüente pelo qual o imigrante passa e pode ser avaliado pelo grau de incerteza que tem após sua chegada em outro lugar. Desta problemática advém o maior dilema do imigrante, que consiste na tensão entre o empenho para uma maior adaptação sociocultural e a preservação da identidade com seu país de origem (Mota, Franco, \& Motta, 1999). Esse estranhamento fica evidente em verbalizações como:

Quando chegamos aqui... tudo parecia muito quente... calor, eu achava que as pessoas falavam muito estranho e na verdade não me adaptei: repeti duas vezes a mesma série, a $7^{\mathrm{a}}$. Pela adaptação da língua. Pelo currículo da escola. (Família 3)

Eu nunca me adaptei a este lugar. Nunca porque tem essas lombas, essas descidas, essas assim... eu não posso caminhar, eu caio... aqui a gente se sente um pouco perdida, um pouco isolada do resto, né? (Família 5)

Chegamos com duas malas e duas crianças. Sem horizonte, sem saber o que fazer... nem para onde ir... só sabíamos que íamos chegar, né? Aí eu me deprimi, não dormia, engordei, engordei... em um mês engordei muito (Família 1).

Cultura pode ser entendida como um conjunto de experiências, crenças e valores, e ser entendida como um campo ativo de luta e contestação, que envolve também estes fatores já citados, mas não apenas eles. Abrange ainda os processos, categorias e conhecimentos através do quais as comunidades são definidas de forma específica e diferenciada. Isso significa que, longe de uma limitação em englobar a tota- lidade de experiências compartilhadas por um determinado grupo, a cultura está implicada com a forma pela qual tais experiências, crenças, tradições perpassam o mundo social e são levadas pelos imigrantes no seu processo migracional (Meyer, 1998).

No processo de aculturação o sentimento e percepção de estranhamento é freqüentemente percebido pelos imigrantes. Nesse caso, desde a topologia da cidade de acolhida até o próprio corpo se constituem para o imigrante como o lugar da diferença. Viñar (2003), ao falar do reconhecimento do outro, refere que o corpo é o mediador entre o mundo exterior e o psiquismo, deixando sempre uma marca. A percepção afetiva permite constituir entre o próprio e o estranho, que neste caso é o estrangeiro. Para o imigrante, esse estranhamento, leva muitas vezes à disfunção emocional (depressão) e repercussões físicas (ganhar peso), como observamos no depoimento de uma entrevistada.

\section{As relações comunitárias}

No processo aculturativo interagem uma variedade de fatores como, a natureza do movimento migratório, status sócio-econômico, idéias de suporte social e a receptividade da cultura de acolhida, moderadores do processo aculturativo (Gregorio Gil, Díaz-Gómez, \& Rivas Nina, 1994; Sabatier \& Berry, 1996; Zepeda, 2000).

A aculturação, enquanto construto teórico que procura explicar o processo de contato direto com uma nova cultura, pode ser entendida como uma forma cumulativa de aprendizagem social que envolve a assimilação de novos padrões culturais por indivíduos que, mesmo assim, mantém valores de sua cultura de origem (Bhattacharya, 2000). Entretanto, mesmo antes da chegada no novo país, as percepções de similaridades e diferenças culturais afetam sua posterior adaptação. As dificuldades idiomáticas são apenas um dos estressores sociais que estas pessoas podem experienciar durante o processo de inter-relação com uma nova cultura.

Eu gosto muito da gente do jeito que são aqui. Aqui as pessoas não reparam se tenho o cabelo curto ou comprido, como ando... as pessoas são iguais, me tratam bem, me falam bem, me tem muita paciência por não falar bem o português. Quando as pessoas notam que sou estrangeira, me ajudam. Tenho me surpreendido muito por isso... As pessoas aqui têm a posição de ajudar... Aqui não existe discriminação (no trabalho, pela profissão); não me sinto discriminada pelos meus gostos, já que praticamente lá meu trabalho é de homens. (Família 3)

Aqui é a mesma coisa que na Argentina, temos alguns amigos distribuídos pela cidade e a gente vai no fim de semana nas casas deles, sai com os colegas de trabalho no sábado, as vizinhas e as minhas alunas se reúnem para tomar mate e nos domingos fazemos churrasco com os vizinhos... Tudo igual que na Argentina, só que agora os amigos são brasileiros. (Família 6)

Atualmente, o Modelo Multicultural de Aculturação parte da inclusão dos grupos etnoculturais dentro do sistema majoritário em que se encontram em contato permanente e 
que são produtores de mudanças culturais nos dois sentidos, adquirindo novos conhecimentos e experiências para ambos os grupos. Essa produção acaba gerando uma necessidade de adaptação de ambas as partes, tanto em nível pessoal, como psicológico e sócio-cultural (Sarriera, 2000).

Essa perspectiva de inter-relação entre dois ou mais segmentos culturais inseridos dentro de uma mesma sociedade entra em sintonia com o marco teórico proposto por Bronfenbrenner (1996), para a o entendimento dos processos desenvolvimentais humanos e o proposto por Sarriera (1998), para a compreensão da dimensão psicossocial de uma comunidade. Essas propostas pressupõem "trocas" sistêmicas entre as várias dimensões da sociedade, através de seus sistemas, em uma perspectiva ecológica (Kelly, 1992).

\section{A identidade e as expectativas de vida}

Mesmo a personalidade, que se estrutura parcialmente na relação com a cultura e a partir das necessidades biopsicológicas individuais, sofre as conseqüências de processos aculturativos intersocietais. A partir disso, surge na etnopsicologia o estudo psicológico em diferentes etnias, e seu avanço contribui, em grande parte, para as pesquisas transculturais (Boneva \& Frieze, 2001; Sebben, 1999).

Uma das mais importantes descobertas das teorias da etnicidade é que a identidade étnica nunca se define de maneira puramente endógena, pela transmissão da essência e das qualidades étnicas por meio do membership; ela é sempre e inevitavelmente um produto de atos significativos em relação a outros grupos (Barth, 1969/1998; Poutignat \& StreiffFenarth, 1998).

A identidade se constrói na relação entre a categorização pelos não-membros e a identificação com um grupo étnico particular. A pertença a um grupo étnico é questão de definição social, de interação entre a autodefinição dos membros e a definição dos outros grupos. É esta relação dialética entre as definições exógena e endógena de pertença étnica que transforma a etnicidade em um processo dinâmico sempre sujeito à redefinição e à recomposição.

Lá na Argentina não escutava, por exemplo, tango. Tango eu nunca gostei. Agora quando escuto tango, bah. Que saudade! Parece que fala de mim, para mim... (Família 6)

Lá (no país de origem) caras incompetentes, mal preparados, sem profissão conseguem emprego... e aqui no Brasil as pessoas entram (no mercado laboral) pela sua capacidade... se eu me preparo academicamente para conseguir um emprego, vou ganhar.

A identidade do imigrante passa por uma crise inicial permeando sua existência (Sayad, 1998). Não só o imigrante tem de continuar tendo uma identidade com seu país de origem, mas parece que em certos momentos deve fazê-la aparecer mais e para isto recorre a elementos culturais dos quais não precisava ao morar no seu próprio país. O que na cotidianidade da sua nação não tinha muita relevância, se torna importante a ponto de, como no caso da música, passar a ter um sentido que fala de sim próprio.
De outro lado, o anseio por melhorar o nível econômico leva os imigrantes a ver de uma outra forma as possibilidades laborais, acreditando que o emprego é conseguido no país de acolhida de formas muito diferentes daquelas do país de origem. Nesse caso, a visão que têm do Brasil, ao contrário do achado por Sayad (1998), não é de medo, desconfiança; mas de esperança e possibilidades.

A aculturação de imigrantes em uma nova pátria é bastante determinada por fatores econômicos e materiais. Estes fatores muitas vezes determinam tipos de imigrantes. O primeiro é aquele imigrante que já sai de sua terra decidido a não voltar. Qualquer lugar deve ser mais fácil de viver do que lá. O segundo é o imigrante que sai pensando em voltar assim que consiga juntar algum dinheiro, e consegue. Já o terceiro tipo, possui os mesmos planos do segundo, mas não consegue voltar para seu país. É o tipo “frustrado”, que acaba ficando na nova terra por não ter condições de sair. E o último tipo, avaliado por Klein (1999) como o mais freqüente historicamente até 1915, é o imigrante que tinha os mesmos planos dos dois últimos, mas quando chegava à nova terra prosperava econômica e socialmente e decidia ficar e integrar-se à nova terra (Klein, 1999).

No caso dos imigrantes, não se pode falar de sua construção cultural em um novo país como se fosse idêntica à produção em seu país de origem. Trata-se de um estilo de vida, atitudes, conceitos e hábitos que são diferentes da cultura majoritária, ao mesmo tempo em que diferem da cultura de origem. Essa diferença é explicada pela relação de equilíbrio entre a pressão ambiental e a manutenção cultural (Pozenato, 2000).

Fazer vir à tona a afirmação da própria diferença só se torna possível depois que o sucesso, principalmente o econômico, se torna visível e inquestionável por parte dos que integram a cultura majoritária (Pozenato, 2000). Entretanto, essa afirmação só tem sentido se for ressignificada em termos de elementos comuns de identidade. A motivação para a manutenção de uma identidade de imigrante, ou pelo menos de “estranho” à cultura majoritária é proporcional às possibilidades, mesmo que apenas fantasiosas, de retorno à pátria de origem (Pozenato, 2000).

\section{Conclusões}

Os resultados encontrados neste estudo demonstram a importância de repensarmos a questão da inserção de grupos minoritários na sociedade brasileira. Assim como se tem avançado em relação à diminuição de diferenças historicamente importantes em relação a grupos marginalizados pela sociedade brasileira, a atenção às diferenças culturais e étnicas também deve ser considerada como foco de ação pela psicologia.

Assim como outros segmentos historicamente marginados (como as mulheres, as populações indígenas e de afro-descendentes, por exemplo), que, em seu momento, conseguiram reivindicar e alterar uma série de estereótipos e preconceitos sócio-culturalmente construídos, os grupos de imigrantes também devem ser considerados como metas no processo de inclusão e desenvolvimento social do Brasil. 
Historicamente, as relações étnicas e raciais têm sido importantes tópicos em investigação social. Entretanto, muito dessa investigação foi abandonada ou disfarçada em nome de certa preocupação de que diferenças entre grupos étnicos e ou culturais pudessem ser mal utilizadas em fins sociais e políticos, posto que muito do conhecimento gerado nesta direção foi utilizado para a perseguição, exclusão ou extermínio de grupos étnicos em diversas culturas.

Todavia, recentemente surgiram novos construtos e perspectivas de investigação na busca do entendimento das relações interétnicas. Além dos processos aculturativos, compreendidos aqui desde uma perspectiva ecológica, segundo a qual tanto os imigrantes quanto a comunidade de acolhida estão igualmente implicados no processo (Sarriera, 2000), os resultados desta investigação apontam em direção a um conceito importante na compreensão das relações comunitárias com grupos de origens diferentes: a identidade étnica.

A identidade étnica pode se estabelecer, ou se manter, em termos de redes de apoio ou movimentos sociais. A funcionalidade da manutenção de uma identidade étnica, ou mesmo seu processo de construção entre imigrantes, deve ser analisado através da historiografia de sua presença em um dado meio, considerando os diferentes contextos (Constantino, 2000).

A identidade étnica é uma construção cultural que se realiza em um período de tempo histórico, no qual grupos étnicos em situações reais se recriam constantemente e a etnicidade é sempre reinventada para fazer frente à realidade que muda (Constantino, 2000).

O simples fato de diferenças étnicas existirem dentro de uma mesma cultura, por exemplo, não identifica os elementos da amplitude do sistema de crenças culturais que direcionam as conseqüências desenvolvimentais específicas; não apenas seu conhecimento das interações, mas a natureza multidimensional de diferentes níveis neste sistema (McLaren, 1995).

Um dos espaços mais privilegiados para a avaliação e reprodução das influências culturais, partindo-se da perspectiva da teoria dos sistemas ecológicos, é o espaço do microssistema familiar. Assim como a escola, as organizações laborais, os sistemas comunitários, a família fornece uma série de elementos psicossociais, fundamentais para o desenvolvimento de seus membros, conforme apontam os participantes da pesquisa (Sarriera, Dellazzana, Silveira, Pizzinato, \& Rangel, 2002).

É possível que a família muitas vezes se veja ameaçada no que possui de mais fundamental: dar a seus membros a identidade de base suficientemente segura para enfrentar os acontecimentos da vida. A família imigrante precisa reordenar, dentro de um novo contexto cultural, dimensões muito particulares da experiência humana: tempo de vida, de aprendizagem, de educação, de reprodução, etc., que na atual conjuntura social, muitas vezes ficam a cargo de outras instituições sociais.

O marco dos sistemas ecológicos permite estudar a família como um sistema imerso dentro de outros sistemas. Em um sistema e, portanto, nas famílias, cada elemento afeta a ou- tros e é por sua vez afetado por eles em uma espécie de equilíbrio circular que, uma vez estabelecido, tende a manter-se. Isso é o que se chama de tendência à homeostase, que é a tendência do sistema em permanecer igual a si mesmo.

Os dados desta investigação indicam que no processo migratório interagem, e são retomadas, uma série de experiências vitais. No processo de inserção na comunidade de acolhida os relacionamentos interpessoais e a forma de dirigi-los são fundamentais, tanto como fator mediador, quanto como fator preditor de saúde mental e desenvolvimento saudável.

Este estudo, portanto, direciona-se à compreensão de aspectos práticos da inserção de imigrantes em contextos de nossa comunidade, no que se consideram suas trajetórias e os aspectos identitários e culturais envolvidos no processo de inserção.

É fundamental, a partir desse quadro, que sejam desenvolvidos programas de inserção, assessoria e suporte ao local que funciona como "pano de fundo" para essas situações: a comunidade de acolhida. A comunidade deve ser instrumentalizada para poder mediar de forma mais eficaz o processo de inserção social por que passam imigrantes e demais "diferentes".

As famílias aqui apresentadas encontram-se em um processo de inserção na comunidade, embora haja aspectos obstaculizantes no contexto de acolhida (como por exemplo, as questões de documentação, preconceito e da crise no mercado laboral). Possivelmente os aspectos da história familiar e as expectativas de desenvolvimento, por outro lado, servem como fatores motivadores da inserção na cultura local.

Seria imprescindível a implementação de programas que possibilitem um atendimento das necessidades específicas do desenvolvimento de crianças imigrantes, de maneira a que possam ser oferecidas melhores condições de crescimento e inserção social a este grupo.

Para tanto, é fundamental uma sensibilização, não apenas de integrantes da comunidade direta, mas de legisladores e geradores de políticas publicas que possam, de fato, aproximar-se de forma mais eficaz e engajada dessa temática. Entretanto, se considerarmos como referência o pronunciamento de posse do Presidente Luís Inácio Lula da Silva, a perspectiva assimilacionista segue presente no imaginário político nacional (Silva, 2003).

No discurso do Presidente, ao mesmo tempo em que figura a afirmação de que o Brasil está aberto à recepção de todo e qualquer tipo de imigrantes, afirma que isso é possível porque logo se transformam em "brasileiros", depois de chegarem. Tais afirmações denotam que a perspectiva de absorção dos elementos estrangeiros se mantém no ideário político nacional desde o período imperial, até os dias de hoje, embora menos explícita e “racial” do que outrora (Lesser, 2001).

Em vez de pleitear-se uma integração de pessoas em um processo de cidadania indiferenciado, ainda se pretende "transformar" o diferente. Ainda se pressupõe que os imigrantes devam converter-se em brasileiros. Mas o que isso significa? O que é ser brasileiro? É ter um papel lhe atestando; um passaporte verde? Que tipo de sentimentos, de 
compartilhamentos atestam que alguém é brasileiro? No que isso é importante mesmo?

É necessário que se reconsiderem aspectos como estes, para que o discurso de tolerância possa ser alterado em direção à perspectiva integrativa. Toleram-se muitas coisas desagradáveis na vida, sem que com isso sejam aceitas. Aceitar as diferenças é um processo de conscientização social que deve ser trabalhado, principalmente no contexto educativo.

Mas, acima de tudo é preciso que sejam revistas nossas formas unilaterais e assimilacionistas de encarar o processo de inserção de imigrantes em nossa comunidade. Existe, nesta questão, uma responsabilidade social que recai sobre cada um de nós e sobre nossa sociedade como um todo. Uma sociedade que hoje se orgulha tanto de suas raízes européias deveria encarar de forma mais cidadã a inserção de segmentos humanos advindos de origens étnicas distintas.

Por fim, a teoria dos sistemas ecológicos permite compreender o processo migracional em quanto este acontece desde o microssistema familiar, que deve organizar-se desde o planejamento da saída de sua casa e país, deixando para trás a segurança do contexto conhecido para inserir-se em outros mesossistemas com os quais deverá iniciar novos relacionamentos. Os processos migracionais permitem que as culturas interajam no mundo globalizado; os imigrantes levam para os países de acolhida os costumes e usos culturais que lentamente vão sendo utilizados e apropriados pelas pessoas com quem compartem seu entorno, como colegas da escola dos filhos, depois os pais destes, colegas do trabalho e vizinhos, mostrando como, de fato, este processo é bidirecional (Sarriera, 2000), afetando tanto aos que ingressam na nova cultura, como a quem os recepciona. Finalmente, no macrossistema o processo migracional faz pensar os estados que recebem grande número de imigrantes nas políticas de migração, as quais devem ser adequadas tanto para os que chegam como para os cidadãos, avaliando os recursos disponíveis nos países mais procurados em termos de possibilidades para assentar as famílias, prover vagas para trabalho, educação, saúde e saneamento básico para todos os moradores nos territórios nacionais.

Desta forma, a teoria ecológico-contextual permite não só ter uma compreensão do indivíduo como imigrante, mas as relações que estabelece nos diversos sistemas do seu desenvolvimento, permitindo desta forma avaliar, também, a totalidade do macro contexto em que ocorre o desenvolvimento humano.

\section{Referências}

Albeche, D. (1996). Imagens do gaúcho: história e mitificação. Porto Alegre: Edipucrs.

Barth, F. (1969/1998). Ethnic group and boundaries: the social organization of cultural difference. Oslo: Johansen \& Nielsen Boktrykeri.

Berry, J. (2001). A Psychology of Immigration. Journal of Social Issues, 57(3), 615-631.

Bhattacharya, G. (2000). The school adjustment of South Asian immigrant children in the United States. Adolescence, 35(137), 77-85.

Boneva, B. S., \& Frieze, I. H. (2001). Toward a concept of a migrant personality. Journal of Social Issues, 57(3), 477-491.
Bronfenbrenner, U. (1996). A ecologia do desenvolvimento humano. Porto Alegre: Artes Médicas.

Clemente-Díaz, M. (1992). Métodos y técnicas de investigación. Madri: Eudema.

Constantino, N. S. de (2000). Italianidade(s): imigrantes no Brasil meridional. In F. Carboni \& M. Maestri (Orgs.), Raízes italianas do Rio Grande do Sul: 1875-1997 (pp. 65-80). Passo Fundo: Universidade de Passo Fundo.

Departamento de Polícia Federal. (2000). Relatório Governamental. Divisão de Polícia Marítima, Aeroportuária e de Fronteiras - Serviço de Registro de Estrangeiros, manuscrito não-publicado, Porto Alegre.

Diégues Júnior, M. (1964). Imigração, urbanização, industrialização. Rio de Janeiro: Centro Brasileiro de Pesquisas Educacionais, Ministério da Educação e da Cultura.

Fagundes, A. A. (1992). E o gaúcho morreu? In L. C. Fisher \& S. Gonzaga (Orgs.), Nós os gaúchos (pp. 24-43). Porto Alegre: Editora da Universidade.

García, Martínez, \& Santolaya, (2002). Inmigración, intervención social e interculturalidad en el ámbito comunitario. Universidad de Granada, España: Laboratorio de Estudios Interculturales.

González-Tornaría, M. L. (2000). Familia y educación en valores. Sala de Lectura: Organización de Estados Iberoamericanos para la Educación, la Ciencia y la Cultura. Hipertexto disponível em: http://www.campus-oei.org/ valores/tornaria.htm.

Gregório Gil, C., Díaz-Gómez, M. C., \& Rivas Nina, M. (1994). Guia de apoyo para el profesional de la intervención con inmigrantes economicos y refugiados. Madri: Colégio Oficial de Psicólogos.

Instituto Brasileiro de Geografia e Estatística - IBGE (2000). Censo demográfico populacional. Porto Alegre: Sistema IBGE de Recuperação de Dados - SIDRA.

Kelly, J. (1992). Psicología comunitaria: el enfoque ecológico contextualista. Buenos Aires: Centro Editor de América Latina.

Klein, H. S. (1999). Migração internacional na história das Américas. In B. Fausto (Org.), Fazer a América (pp. 13-32). São Paulo: Editora da Universidade de São Paulo.

Lesser, J. (2001). A negociação da identidade nacional: imigrantes, minorias e a luta pela etnicidade no Brasil. São Paulo: EDUNESP.

Martínez G. R. A. (1996). Familias y escuelas. In G. R. A. Martínez (Org.), Psicología de la familia. Un enfoque evolutivo y sistémico (Vol. 1). Valencia: Promolibro.

McLaren, P. (1995). Multiculturalismo revolucionário: pedagogia do dissenso para o novo milênio. Porto Alegre: Artmed.

Meyer, D. (1998). Alguns são mais iguais que os outros: etnia raça e nação em ação no currículo escolar. In L. Silva (Org.), A escola cidadã no contexto da globalização (pp. 369-380). Petrópolis: Vozes.

Mota, E., Franco, A., \& Motta, M. (1999). Migração, estresse e fatores psicossociais na determinação da saúde da criança. Psicologia: Reflexão e Crítica, 12(1), 119-132.

Pereda, C., Prada, M. D., \& Actis, W. (1999). Inmigrantes, trabajadores, ciudadanos: una visión de la migraciones desde España. Valencia: Patronat Sud-Nord, Universitat de Valencia.

Poutignat, P., \& Streiff-Fenart, J. (1998). Teorias da etnicidade. São Paulo: EDUNESP.

Pozenato, J. C. (2000). A cultura da imigração italiana. In F. Carboni \& M. Maestri (Orgs.), Raízes italianas do Rio Grande do Sul: 1875-1997 (pp.115128). Passo Fundo: Universidade de Passo Fundo.

Sabatier, C., \& Berry, J. (1996). Inmigración y aculturación. In R. Y. Bourhis \& J.-P. Leyens (Orgs.), Estereótipos, discriminacón y relaciones entre grupos (pp. 217-241). Madri: Mc Graw Hill.

Sarriera, J. C. (1998). O modelo ecológico-contextual em psicologia comunitária. In L. Souza, M. Freitas, \& M. Rodrigues (Orgs.), Psicologia: reflexões (im)pertinentes (pp. 373-396). São Paulo: Casa do Psicólogo.

Sarriera, J. C. (2000). Educação para a integração entre culturas e povos: da aculturação para o multiculturalismo. In J. C. Sarriera (Org.), Psicologia comunitária: estudos atuais (pp. 179-202). Porto Alegre: Sulina. 
Sarriera, J. C., Silveira, P. G., Dellazzana, L., Pizzinato, A., \& Rangel, M. P. (2002). La inserción social de la familia inmigrante. Cuadernos de Terapia Familiar, 2(50), 45-56.

Sayad, A. (1998). A migração ou os paradoxos da alteridade. São Paulo: Editora da Universidade de São Paulo.

Sciarra, D. T. (1999). Multiculturalism in couseling. Itasca: Peacock.

Sebben, A. (1999). Um estudo exploratório sobre intercâmbio cultural entre adolescentes brasileiros com a contribuição da psicologia e da educação.
Dissertação de mestrado não-publicada, Universidade Federal de Santa Catarina, Florianópolis.

Silva, L. I. L. (2003, 2 de janeiro). Discurso de posse do Presidente da República Federativa do Brasil. Zero Hora, Caderno da Posse, pp. 3-5.

Viñar, M. (2003). El reconocimiento del prójimo. In F. Blanck-Cereijido \& P. Yankelevich (Orgs), El otro, el extranjero (pp. 35-48). Buenos Aires: Libros el Zorzal.

Zepeda, M. (2000). Parental ideas about infant development: do they differ with acculturation status? Los Angeles: California State University Press.

Jorge Castellá Sarriera, doutor em Psicologia Social pela Universidad Autónoma de Madrid (Espanha), é professor na Faculdade de Psicologia e Coordenador do Grupo de Pesquisa em Psicologia Comunitária da Pontifícia Universidade Católica do Rio Grande do Sul e pesquisador do CNPq. Endereço para correspondência: Av. Protásio Alves, 7149, Blc. 6, apto. 703; Porto Alegre, RS; 91310-003; E-mail: sarriera@pucrs.br Adolfo Pizzinato, mestre em Psicologia Social e da Personalidade (PUCRS), é doutorando em Psicologia da Educação na Universitat Autónoma de Barcelona (Espanha), bolsista CAPES e membro do Grupo de Pesquisa em Psicologia Comunitária da PUCRS. E-mail: adolfopizzinato@yahoo.com.br María Piedad Rangel Meneses, mestre em Psicologia Social e da Personalidade (PUCRS), doutoranda em Psicologia (PUCRS) e bolsista CAPES, é professora na Faculdade de Psicologia da Universidade Regional Integrada do Alto Uruguai e das Missões e membro do Grupo de Pesquisa em Psicologia Comunitária da PUCRS. E-mail: piarangelm@gmail.com 